\title{
Growing Sage
}

\author{
Susan Kemper
}

Roberts Distinguished Professor, Psychology

Senior Scientist, Gerontology, University of Kansas

his Merrill Retreat has taught me a lot about the challenges facing our
universities and possible solutions to those challenges. I've heard about the
role of capital campaigns and political action committees, F\&A reimbursement policies, and 'deliverables' and 'consumables.' Most of all, I've heard a lot about recruiting new faculty to fill gaps in our research networks. But once we've aggressively recruited new faculty, with remodeled laboratories, start-up packages, and teaching reductions, what then? We have an impressive array of programs designed to launch the research careers of our junior faculty - but KU, and I assume most of our peer institutions, seem to have few programs in place to sustain and enhance the research of mid-career and senior faculty.

The Provost's website lists the Big 12 Fellowship, the Keeler IntraUniversity Professorship, and Sabbatical Leaves under "faculty development." With a little more digging, I found some short-term residencies and fellowships offered by the Hall Center and other units. And there is the General Research Fund and other internal monies provided by KUCR including funds to support research-related travel and proposal preparation. The promise of our current focus on measuring research engagement is that it will help us identify ways to support and sustain research engagement and I hope it lives up to this promise and considers how to do so across 20 - 30 - 40 year career horizons.

My concerns are driven in part by my own situation. I've been at KU 32 years. When I started in 1978, I didn't get any sort of start-up package, I had to make do with a lab room that hadn't even been emptied out of the junk and debris abandoned by its prior occupant, and I never saw a teaching reduction until I bought out most of my teaching obligations using a KO1 award from $\mathrm{NIH}$. While in the past few years, I've enjoyed, and made very good use of, the funds generously provided by the Roberts Endowment to build eyetracker labs, attend workshops on neuroimaging, SEM, and new technologies to support aging in place, most of those in my same cohort have struggled to replace and upgrade research equipment, to adapt out-dated research space to contemporary needs, and to acquire expertise in new techniques and technologies. And many have left $\mathrm{KU}$, enticed away to greener pastures. While we aggressively recruit 
and support junior faculty, our current crop of mid-career and senior faculty are often overlooked, yet I want to argue that sustaining the University's research productivity depends on them.

I take the title of my remarks from Winston Churchill who, on the occasion of his $80^{\text {th }}$ birthday reminded us "We are happier in many ways when we are old than when we are young. The young sow wild oats. The old grow sage." I would revise it somewhat to place the emphasis on 'productivity' not happiness. The wild oats sown by the young may fall on non-fertile ground, may be washed away by floods, or fall victim to rust, or smut, or blight. But sage is a hardy plant that struggles to return year after year and my concern is with its cultivation.

Most discussions of research productivity and senior faculty start and end with a consideration of the implications of the elimination of mandatory retirement policies in 1994 And they are almost always coupled with dire prognostications about the aging professorate: aging faculty are assumed to be nonproductive at best. We are criticized for 'consuming excessive salaries,' held responsible for the alarming rise in the costs of health insurance, viewed as dull and obsolete, and damned for blocking the careers of more dynamic, and younger, faculty. These prognostications raise the specter not of a campus alive with dynamic, innovative, and productive young faculty, but one clogged with geriatric professors waving canes in one hand and tattered, yellow lecture notes in the other.
Lest you think this view is itself outdated, consider this recent interview with Paul Romer (Tabarrok, 2009). Romer is an economist at Stanford, specializing in economic growth and he is commenting on the rise in the age of NIH grant recipients: "If we are not careful, we could let our institutions, things like tenure and hierarchical structures and peer review, slowly morph over time so that the old guys control more and more of what's going on and the young people have a harder and harder time doing something really different and that would be a bad thing for these processes of growth and change."

It is not just NIH that is plagued by a changing demographic; another recent review (Alexander \& Liu, 2009) called attention to the aging of medical school faculty, urging medical schools to focus on the recruitment and retention of new faculty while managing the financial costs of faculty who "postpone" retirement.

These two issues have received a lot of recent attention in the Chronicle of Higher Education, including a recent essay (Phelps, 2010) that argued that "retirement is central to the renewal of the American university." The author went on the urge us to "make a timely retirement alluring..." by inspiring faculty to "envision their retirement."

This is indeed a timely issue. Recently, the Silicon Valley Mercury News (Krieger, 2010) reported on "Stanford's graying faculty" highlighting a 74 year old English professor, a 84 year old physicist, and an 79 year old nanotechnologist. The piece included these alarming quotes from 
Larry Summers that an aging faculty "is one of the profound problems facing the American research university...It defies belief that the best way to advance creative thought, to educate the young, or to choose the next generation of faculty members is to have a tenured faculty with more people over 70 than under 40." And Stanford's Provost lamented "If too many older scholars prevent the younger generation's advancement, bright students may not go into academia...We really narrow down to a tiny trickle the amount of new people - the new geophysicists, the new economists, or the new civil and environmental engineers," he said. "The health of the research enterprise of the country really depends on getting young people to choose academia as a career."

To return to my agrarian metaphor, to ensure a good crop, the assumption seems to be that we must plow under the sage to make room for the oats. I want to challenge this assumption.

1. Eliminating mandatory retirement did not result in a geriatric faculty. There is actually data on this topic. Some of you may be familiar with an analysis by Holden and Hansen (2000) of the impact of retirement policies on North Carolina's research universities. After extensive analyses, they concluded that late retirements are more than offset by early retirements, the mean age of retirement has not increased, and few faculty are 65 or older.

And the National Survey of Postsecondary Faculty (USDE, 2008) has shown that there has been a right-ward shift in the mean age of faculty but faculty distributions remain "right-censored." There's been no rise nationally in the numbers of faculty 65 and older about $4 \%$ of faculty are 65 or older and this fraction has been holding steady since the 1990s. Stanford appears to be an exception to this national trend, with $10 \%$ of their faculty $65+$.

2. The "aging" of the professorate is not a result of faculty members 'postponing' retirement but reflects that 'scarcity' of young faculty members. Holden and Hansen (2000) as well as other surveys (Bland \& Bergquist, 1997) have identified a number of demographic changes that affect the age distribution of faculty: our "young" faculty are 10 or more years older on average than those hired in the 1970s and 1980s. Individuals postpone entering graduate school, postpone finishing doctoral degrees, postpone entering the academy for personal, professional, and financial reasons; and we have a variety of policies and practices in place that further serve to 'age' the faculty, not the least of which will be long-term implications of recent hiring freezes.

3. But what I most want to take issue with the assumption that older faculty members are 'nonproductive' and 'noncreative.' This view of the relationship between age and achievement is widely held and deeply entrenched.

It owes a lot to a series of analyses by Lehman (1953) in the 1950s; he charted the relationship between age and achievement in many different domains, from creative contributions to German grand operas and chess championships to publications in psychology and medical specialties like pathology and surgical technique. His consistent finding was that achievement 
peaks in the 30s - somewhat earlier in some domains like chess, somewhat later in others like medicine.

However, these data, and lots of more recent data both cross-sectional and longitudinal, have been reanalyzed by Simonton (1997). He's found that it is 'career' age, not chronological age, that determines research and creative productivity. Historically, individuals launched their careers in their early 20s, and following a 10-year period of apprenticeship and training, hit their peaks in their mid-30s. But Simonton's point is that it's that 10-year investment that 's critical, not the age at which you launch your career. Simonton has modeled productivity as reflecting 3 parameters: what he terms creative potential, ideation rate, and elaboration rate. Creative potential is a 'free parameter' that varies across individuals - it is the pool of new ideas, concepts, variations, and innovations that an individual can draw upon. Ideation rate varies across disciplines and refers to how rapidly those potential ideas can be combined, implemented, and operationalized; elaboration rate also varies across disciplines and refers to how rapidly those idea combinations can be turned into papers and products. The sciences, humanities, and arts differ in the later 2 parameters, allowing for somewhat later peaks in the humanities and somewhat earlier peaks in the sciences. Simonton has found that productivity peaks at career age of 22 , so that if you enter a profession at chronological age of 30, you'll hit your peak at age 52 and your output won't zero-out until age 70 .
Simonton has also demonstrated what he describes as the "longitudinal stability of cross-sectional variation in productivity." He explains "those who are the most productive in the early part of the career are also the most productive at the career peak as well as the most productive toward the end of life." Simonton has contrasted 2 explanations for this: an explanation that assumes that early productivity results in the most incentives and rewards and a more parsimonious one that just assumes individual variation in creative potential predicts long-term productivity. He has rejected the first in favor of the second: high creative potential not only drives the age at which you hit your peak, but productivity over your entire career.

Others have also challenged Lehman's view of productivity as taking a sharp downward plunge after peaking in the 30s. For example, Gingras et al. (2008) looked longitudinally at the careers of 13,000 professors from Quebec, tallying up publications and assessing the impact of those publications. They contrasted data pooled across all professors with that from a subset of professors who actually published in their fields. They point out that the proportion of 'active' faculty does decline with advancing age, peaking in the $40 \mathrm{~s}$ at about $65 \%$, declining to about $50 \%$ for those in their 60s. However, they show that "active" professors hit a peak rate of productivity in their 40s and sustain their rate of productivity throughout their 50s and 60s. Their impact is somewhat curvilinear, with their 'best' works 
coming both early and late in their careers.

4. And I would add: Aging ain't all bad. As pointed out by a recent survey of academic leadership (American Council on Education, 2008), while $12 \%$ of tenured faculty are 61 or older, $49 \%$ of university presidents and chancellors are 61 or older.

Finally, let me remind you the findings of Shimamura, Berry, Mangels, Rustings, \& Jurica (1995). They assessed the performance of a panel of University of California, Berkeley faculty, between 30 and 71 years of age, on a battery of tests of memory and cognition. They compared their performance to that of a group of well-educated, community dwelling older adults and to that of a group of UC-Berkeley undergraduates. On these tests of processing speed, conceptual learning, and prose memory, they found the 'typical' age-related decline when the community-dwelling older adults were compared to the college students. And they also did so when they examined speed of processing for the faculty members. However, on the tests of learning and retention, they found that the older faculty members did just as well as the younger ones. Similar findings have been reported elsewhere when expertise has been assessed - while general abilities may decline, expertise may be preserved, perhaps through selective optimization, the development of compensatory skills, the formation of highly specialized knowledge, or the deployment of additional effort and practice. Indeed, analyses of the relationship between age and job performance across a wide range of domains has found a zero relationship (Charness \& Krampe, 2008).

So my conclusions should be obvious:

- The elimination of mandatory retirement isn't the problem

- The scarcity of young faculty is a problem

- Productive faculty remain productive

- We can and do age successfully

- We need to adjust our time scales to consider how to support the careers of productive faculty members for 20 or 30 or indeed 40 years.

While we do need to plant and fertilize a crop of young faculty members, we shouldn't just plow under the old. The key to sustaining and enhancing research productivity lies with taking the long-view of research careers as extending well past attaining tenure. The age distribution of our faculties is shifting, in part reflecting global demographics and the 'extension of childhood' and the compression of morbidities as we adjust to the prospect of long lives.

So why DO we value the young? If Simonton is right, productivity and creativity aren't the exclusive domain of the young. I think we value the young because they bring new ideas and new technologies to the academy - ones they have acquired during their recent period of training and apprenticeship. So if we want to support and sustain the research productivity of our mid-career and senior faculty, we need to reinvest in them. I have some suggestions as to how to do so: 
1. Let's shorten the interval between sabbaticals, remove the quota, support full-pay for academic year leaves.

2. Let's support on- and off-campus mini-sabbaticals and summer fellowships to enable advanced training in new technologies and techniques for data analysis, digital image analysis, neuroimaging, robotics, comparative effectiveness

\section{References}

Alexander, H., \& Liu, C. Q., (2009). The aging of full-time U. S. medical school faculty, 19672007. AAMC Analysis in Brief, 9, (4).

American Council on Education Center for Policy Analysis (2008). Too many rungs on the ladder? Faculty demographics and the future leadership of higher education. Retrieve at : http: www.acenet.edu.

Bland, C., \& Bergquist, W. (1997). The vitality of senior faculty members. Snow on the roofFire in the furnace. Retrieval at: http://www.eric.ed.gov/ERICDocs/data/ericdo cs2sq/content storage 01/0000019b/80/15/29/3 a.pdf.

Charness, N., \& Krampe, R. T. (2008). Expertise and knowledge. In S. M. Hofer and D. F. Alwin (Eds.), Handbook of Cognitive Aging: Interdisciplinary perspectives (p. 244-259). Thousand Oaks, CA: Sage.

Gingras, Y., Lariviere, V., Macaluso, B., Robitaille, J-P. (2008). The effects of aging of scientists on their publication and citation patterns. Public Library of Science, 3, e4048-4059. research, virtual reality simulations, etc. etc. etc.

3. Let's increase technical support oncampus for new technologies and techniques: the digital humanities and research methods/data analysis centers are good starts but we need to expand these centers and develop new ones in key areas in the arts, the social and behavioral sciences, and in the humanities on par with those the biosciences and engineering.

Krieger, L. M. (2010). Stanford University confronts the graying of academia. Retrieve at: http://www.mercurynews.com/ci_15480908?n click_check=1.

Lehman, H. C. Age and Achievement. Princeton, NJ: Princeton University Press.

Phelps, C. (2010). We need to see retirement as a hiring issue. The Chronicle Review, April 30, B11-12.

Shimamura, A. P., Berry, J. M., Mangels, J. A., Rusting, C. L., \& Jurica, P. J. (1998). Memory and cognitive abilities of university professors: Evidence for successful aging. Psychological Science, 6, 271-277.

Simonton, D. K. (1997). Creative productivity: A predictive and explanatory model of career trajectories and landmarks. Psychological Review, 104, 66-89.

Tabarrok, A. (2009). Aging academia. The Economist, 16, 31.

USDE, National Center for Education Statistics, (2008). National Study of Postsecondary Faculty. 